\title{
Increased Serum Levels of sCD14 and sCD163 Indicate a Preponderant Role for Monocytes in COVID-19 Immunopathology
}

Jose Gómez-Rial1,2*t, Maria José Currás-Tuala't, Irene Rivero-Calle ${ }^{1,3}$, Alberto Gómez-Carballa1,4, Miriam Cebey-López', Carmen Rodríguez-Tenreiro', Ana Dacosta-Urbieta ${ }^{1,3}$, Carmen Rivero-Velasco ${ }^{5}$, Nuria Rodríguez-Núñez ${ }^{6}$, Rocio Trastoy-Pena ${ }^{7}$, Javier Rodríguez-García ${ }^{8}$, Antonio Salas ${ }^{1,4}$ and Federico Martinón-Torres ${ }^{1,3 *}$

\section{OPEN ACCESS}

Edited by:

Annalisa Del Prete,

University of Brescia, Italy

Reviewed by:

Angela Ceribelli,

Humanitas Research Hospital, Italy Kenneth Williams,

Boston College, United States

${ }^{*}$ Correspondence:

Jose Gómez-Rial

jose.gomez.ria/@sergas.es

Federico Martinón-Torres

federico.martinon.torres@sergas.es

tThese authors have contributed equally to this work

Specialty section:

This article was submitted to Cytokines and Soluble Mediators in Immunity,

a section of the journal

Frontiers in Immunology

Received: 08 May 2020 Accepted: 02 September 2020 Published: 23 September 2020

Citation:

Gómez-Rial J, Currás-Tuala MJ, Rivero-Calle I, Gómez-Carballa A, Cebey-López M,

Rodríguez-Tenreiro $C$, Dacosta-Urbieta A, Rivero-Velasco C, Rodríguez-Núñez N, Trastoy-Pena R,

Rodríguez-García J, Salas A and Martinón-Torres F (2020) Increased Serum Levels of SCD14 and SCD163

Indicate a Preponderant Role for Monocytes in COVID-19 Immunopathology.

Front. Immunol. 11:560381. doi: 10.3389/fimmu.2020.560381
${ }^{1}$ Grupo de Investigación en Genética, Vacunas, Infecciones y Pediatría, Instituto de Investigación Sanitaria de Santiago, Hospital Clinico Universitario and Universidade de Santiago de Compostela, Servizo Galego de Saúde, Galicia, Spain, ${ }^{2}$ Laboratorio de Inmunologia, Servicio de Análisis Clinicos, Hospital Clinico Universitario Santiago de Compostela, Servizo Galego de Saúde, Galicia, Spain, ${ }^{3}$ Translational Pediatrics and Infectious Diseases Section, Department of Pediatrics, Hospital Clinico Universitario de Santiago de Compostela, Galicia, Spain, ${ }^{4}$ Unidade de Xenética, Instituto de Ciencias Forenses, Facultade de Medicina, Universidade de Santiago de Compostela, and GenPoB Research Group, Instituto de Investigación Sanitaria (IDIS), Hospital Clinico Universitario de Santiago, Servizo Galego de Saúde, Galicia, Spain, ${ }^{5}$ Intensive Medicine Department, Hospital Clinico Universitario de Santiago de Compostela, Galicia, Spain, ${ }^{6}$ Pneumology Department, Hospital Clinico Universitario de Santiago de Compostela, Galicia, Spain, ${ }^{7}$ Microbiology Department, Hospital Clinico Universitario de Santiago de Compostela, Galicia, Spain, ${ }^{8}$ Clinical Biochemistry Laboratory, Hospital Clinico Universitario de Santiago de Compostela, Galicia, Spain

Background: Emerging evidence indicates a potential role for monocytes in COVID-19 immunopathology. We investigated two soluble markers of monocyte activation, sCD14 and SCD163, in COVID-19 patients, with the aim of characterizing their potential role in monocyte-macrophage disease immunopathology. To the best of our knowledge, this is the first study of its kind.

Methods: Fifty-nine SARS-Cov-2 positive hospitalized patients, classified according to ICU or non-ICU admission requirement, were prospectively recruited and analyzed by ELISA for levels of sCD14 and SCD163, along with other laboratory parameters, and compared to a healthy control group.

Results: SCD14 and SCD163 levels were significantly higher among COVID-19 patients, independently of ICU admission requirement, compared to the control group. We found a significant correlation between SCD14 levels and other inflammatory markers, particularly Interleukin-6, in the non-ICU patients group. SCD163 showed a moderate positive correlation with the time lapsed from admission to sampling, independently of severity group. Treatment with corticoids showed an interference with sCD14 levels, whereas hydroxychloroquine and tocilizumab did not.

Conclusions: Monocyte-macrophage activation markers are increased and correlate with other inflammatory markers in SARS-Cov-2 infection, in association to hospital admission. These data suggest a preponderant role for monocyte-macrophage activation in the development of immunopathology of COVID-19 patients.

Keywords: COVID-19, monocyte, sCD14, sCD163, immunopathology 


\section{INTRODUCTION}

Emerging evidence from SARS-Cov-2 infected patients suggests a key role for monocyte-macrophage in the immunopathology of COVID-19 infection, with a predominant monocytederived macrophage infiltration observed in severely damaged lungs (1), and morphological and inflammation-related changes in peripheral blood monocytes that correlate with the patients' outcome (2). An overexuberant inflammatory immune response with production of a cytokine storm and T-cell immunosuppression are the main hallmarks of severity in these patients (3). This clinical course resembles viral-associated hemophagocytic syndrome (VAHS), a rare severe complication of various viral infections mediated by proinflammatory cytokines, resulting in multiorgan failure and death (4). A chronic expansion of inflammatory monocytes and over-activation of macrophages have been extensively described in this syndrome (5-7). Viral-associated hemophagocytic syndrome has been identified as a major contributor to death of patients in past pandemics caused by coronaviruses (8), including previous SARS and MERS outbreaks (9), and currently suggested for SARS-Cov-2 outbreak (10).

CD14 and CD163 are both myeloid differentiation markers found primarily on monocytes and macrophages, and detection of soluble release of both in plasma is considered a good biomarker of monocyte-macrophage activation (11, 12). Elevated plasma levels of soluble CD14 (sCD14) are associated to poor prognosis in VIH-infected patients, are a strong predictor of morbidity and mortality $(13,14)$, and associated with diminished CD4+-T cell restoration (15). In addition, soluble CD163 (sCD163) plasma levels are a good proxy for monocyte expansion and disease progression during HIV infection (16). In measles infection, a leading cause of death associated with increased susceptibility to secondary infections and immunosuppression, sCD14 and sCD163 levels have been found to be significantly higher, indicating an important and persistent monocyte-macrophage activation (17).

We hypothesized that monocytes/macrophages may be an important component of immunopathology associated to SARS-Cov-2 infection. In this paper, we analyze serum levels of soluble monocyte activation markers in COVID19 patients and their correlation with severity and other inflammatory markers.

\section{MATERIALS AND METHODS}

\section{Subjects}

We recruited 59 patients with confirmed PCR-positive diagnosis of SARS-Cov-2 infection, classified according to ICU admission requirement ( $n=22$ patients), or non-ICU requirement $(n=37)$, and age-matched healthy individuals $(n=20)$ as a control group. Demographic data, main medication treatment and routine lab clinical parameters including inflammatory biomarkers were collected for all infected patients. Leftover sera samples from routine analytical controls were employed for the analysis, after obtaining the corresponding informed consent. Time elapsed from hospital admission to sample extraction was also recorded.

\section{Measurement of SCD14 and SCD163 Serum Levels}

To determine levels of soluble monocyte activation markers in serum specimens, appropriate sandwich ELISA (Quantikine, $\mathrm{R} \& \mathrm{D}$ systems, United Kingdom) were used following manufacturer indications. Briefly, diluted sera samples were incubated for $3 \mathrm{~h}$ at room temperature in the corresponding microplate strips coated with capture antibody. After incubation, strips were washed and incubated with the corresponding Human Antibody conjugate for $1 \mathrm{~h}$. After washing, reactions were revealed and optical density at $450 \mathrm{~nm}$ was determined in a microplate reader. Concentration levels were interpolated from the standard curve using a four-parameter logistic (4-PL) curvefit in Prism8 GraphPad software. Final values were corrected applying the corresponding dilution factor employed.

\section{Statistical Analysis}

Data are expressed as median and interquartile range. All statistical analyses were performed using the statistical package $\mathrm{R}$. Mann-Whitney tests were used for comparison between ICU and non-ICU groups versus healthy controls. Pearson's correlation coefficients were used to quantify the association between sCD14 and sCD163 concentration and other lab parameters in nonICU patients. Data outliers, falling outside the 1.5 interquartile range, were excluded from the statistical analysis. The nominal significance level considered was 0.05 . Bonferroni adjustment was used to account for multiple testing.

\section{RESULTS}

\section{Demographic and Clinical Laboratory Parameters}

Patients in the ICU group showed significant differences when compared to non-ICU group in several clinical laboratory parameters: lymphocytes, ferritin, D-dimer, Lactate dehydrogenase (LDH), procalcitonin (PCT), and Interleukin-6 (IL-6). The absolute value for circulating monocytes did not show significant differences between groups. However, these values may have been distorted by the use of tocilizumab, an IL- 6 blocking drug extensively employed in the ICU group which interferes with monocyte function. Age and time elapsed from admission to sample extraction did not show differences between groups. Values are summarized in Table 1.

\section{Serum Levels for sCD14 and SCD163}

Median levels for sCD14 in sera from ICU patients were 2444.0 (95\%CI: $1914.0-3251.0) \mathrm{ng} / \mathrm{ml}$, compared to 2613.0 (95\%CI: $2266.0-2991.0) \mathrm{ng} / \mathrm{ml}$ in non-ICU patients. The healthy control group median value was 1788.0 (95\%CI: $1615.0-1917.0) \mathrm{ng} / \mathrm{ml}$. We observed significant statistical differences when comparing infected patients against controls $(P$-value $<0.0001)$, however no significant differences were observed between ICU and non-ICU 
TABLE 1 | Demographic and clinical laboratory parameters of patients recruited.

\begin{tabular}{|c|c|c|c|c|}
\hline Parameter & ICU & \multicolumn{2}{|c|}{ non-ICU } & $P$-value \\
\hline \multicolumn{5}{|c|}{ Clinical laboratory parameters } \\
\hline Lymphocytes & $0.54(0.47-1.058)$ & \multicolumn{2}{|c|}{$1.16(0.79-1.62)$} & 0.0004 \\
\hline Monocytes & $0.35(0.16-0.65)$ & \multicolumn{2}{|c|}{$0,42(0.35-0.58)$} & ns \\
\hline Platelets & $264(204.3-354.5)$ & \multicolumn{2}{|c|}{$272(213-413)$} & ns \\
\hline D-Dimer & $3676(1198-8121)$ & \multicolumn{2}{|c|}{$755(413-1033)$} & 0.0002 \\
\hline $\begin{array}{l}\text { Lactate } \\
\text { dehydrogenase } \\
(\mathrm{LDH})\end{array}$ & $677(429-818.5)$ & \multicolumn{2}{|c|}{469 (391-595) } & 0.0188 \\
\hline $\begin{array}{l}\text { C-reactive protein } \\
\text { (CRP) }\end{array}$ & $7.37(2.56-20.51)$ & \multicolumn{2}{|c|}{$4,65(2.16-11.41)$} & ns \\
\hline Procalcitonin (PCT) & $0.22(0.09-0.4)$ & \multicolumn{2}{|c|}{$0.09(0.05-0.21)$} & 0.0305 \\
\hline Ferritin & $1257(837.3-3020)$ & \multicolumn{2}{|c|}{$467(254.5-785)$} & $<0.000$ \\
\hline Interleukin-6 (IL-6) & $83.10(14.45-381.8)$ & \multicolumn{2}{|c|}{$12.70(6.95-46)$} & 0.0014 \\
\hline $\begin{array}{l}\text { Glycosylated } \\
\text { hemoglobin } \\
(\mathrm{Hb} 1 \mathrm{Ac})\end{array}$ & $5.95(5.65-6.47)$ & \multicolumn{2}{|c|}{$6.1(5.7-6.9)$} & ns \\
\hline Troponin-I & $0.021(0.017-0.246)$ & \multicolumn{2}{|c|}{$0.017(0.017-0.019)$} & ns \\
\hline \multicolumn{5}{|c|}{ Time elapsed from admission to sample (days) } \\
\hline & $5(3.75-10)$ & \multicolumn{2}{|c|}{$4(2-6)$} & ns \\
\hline \multicolumn{5}{|l|}{ Age (years) } \\
\hline & $52(48.75-61.25)$ & \multicolumn{2}{|c|}{$52(44-65)$} & ns \\
\hline \multicolumn{5}{|l|}{ Corticoids } \\
\hline & 19/22 (87\%) & \multicolumn{2}{|c|}{$2 / 37(5.4 \%)$} & $<0.000$ \\
\hline \multicolumn{5}{|c|}{ Bold values are significant values. } \\
\hline $\begin{array}{l}\text { TABLE } 2 \text { | Concentr } \\
\text { patients from ICU an }\end{array}$ & $\begin{array}{l}\text { ation }(\mathrm{ng} / \mathrm{ml}) \text { of serum le } \\
\text { hd non-ICU groups, and }\end{array}$ & $\begin{array}{l}\text { levels of SCD1 } \\
\text { d healthy contr }\end{array}$ & $\mathrm{sCD}$ & \\
\hline Concentration & ICU & non-ICU & Healthy & controls \\
\hline sCD14 & $\begin{array}{c}2444.0 \\
(1914.0-3251.0)\end{array}$ & $\begin{array}{c}2613.0 \\
2266.0-2991.0)\end{array}$ & $\begin{array}{r}17 \\
(1615.0\end{array}$ & $\begin{array}{l}38.0 \\
-1917.0)\end{array}$ \\
\hline sCD163 & $\begin{array}{c}911.5 \\
(624.7-1167)\end{array}$ & $\begin{array}{c}910.4 \\
(733.1-1088)\end{array}$ & $\begin{array}{r}4 \varsigma \\
(332.5\end{array}$ & $\begin{array}{l}5.6 \\
-600.7)\end{array}$ \\
\hline
\end{tabular}

Data are represented as median and interquartile range.

groups. Median levels for sCD163 in sera from ICU patients were 911.5 (95\%CI: 624.7-1167.0) ng/ml, and 910.4 (95\%CI: $733.1-$ $1088.0) \mathrm{ng} / \mathrm{ml}$ in non-ICU patients. The healthy control group value was 495.6 (95\%CI: 332.5-600.7) ng/ml. As with sCD14, we observed significant differences for values from infected patients compared to control group $(P$-value $<00001)$, but no differences between ICU and non-ICU infected patients. Values are summarized in Table 2 and Figure 1.

\section{Correlation Between SCD14 and SCD163 Levels and Time Elapsed From Hospital Admission}

We assessed the correlation between sCD14 and sCD163 levels and time elapsed from hospital admission to sample extraction (Figure 2). We found a significant positive correlation between sCD163 levels and time elapsed $\left(r^{2}=0.3246\right.$, $P$-value $=0.0156)$ We did not observe a significant correlation between sCD14 levels and time elapsed from hospital admission to sample extraction.

\section{Correlation Between sCD14 and sCD163 Levels and Clinical Laboratory Parameters}

We found significant correlations between sCD14 and sCD163 levels and several clinical laboratory parameters in infected patients (in these analysis, adjusted significance under Bonferrori correction is 0.01 ), but only in the non-ICU group, possibly reflecting an interference of the use of tocilizumab or corticoids in the ICU group. Levels of sCD14 showed a negative correlation with the absolute value of lymphocytes $\left(r^{2}=-0.5501\right.$, $P$-value $=0.0005)$ and a positive correlation with levels of LDH $\left(r^{2}=0.5906, P\right.$-value $\left.=0.0001\right), \mathrm{CRP}\left(r^{2}=0.6275\right.$, $P$-value $<0.0001)$; PCT $\left(r^{2}=0.4608, P\right.$-value $\left.=0.0091\right)$, and Ferritin $\left(r^{2}=0.4414, P\right.$-value $\left.=0.0090\right)$ (Figure 3). No other significative associations were found with other lab parameters. Levels of sCD163 did not show significant correlation with clinical laboratory parameters (Figure 3). Particularly, IL-6 also showed significant positive correlation with $\operatorname{sCD} 14\left(r^{2}=0.6034\right.$, $P$-value $=0.0003)($ Figure 4).

\section{Effect of Treatment on SCD14 and sCD163 Levels}

We analyzed possible interference of different treatments on sCD14 and sCD163 serum levels for all patients. We found an interference of corticoid treatment on sCD14, levels with median values of 2034 (95\%CI: 1319-3159) $\mathrm{ng} / \mathrm{ml}$ for treated group, and values of 2613 (95\%CI: 2466-2913) ng/ml for nontreated group. Values were significantly lower in corticoid-treated group $(P$-value $=0.0069)$ (Figure 5$)$. No impact was found for corticoids on sCD163 levels. Likewise, hydroxychloroquine and/or tocilizumab were not found to have an impact on sCD14 and sCD163 serum levels.

\section{Correlation Between sCD14 and SCD163 Levels and Hospital Stay}

Levels of sCD14 and sCD163 did not show association with length of hospital stay in both groups. Also, these biomarkers did not show association with the number of days of onset of symptoms.

\section{Age-Dependence of sCD14 and SCD163 Levels}

We analyzed for possible age-dependence of sCD14 and sCD163 levels. Values did not show association between these biomarker levels and the age of patients.

\section{DISCUSSION}

Our results show, for the first time, increased levels of sCD14 and sCD163 in sera from SARS-Cov-2 infected patients admitted to hospital. We did not observe statistical differences when comparing ICU versus non-ICU patients. This is probably due 

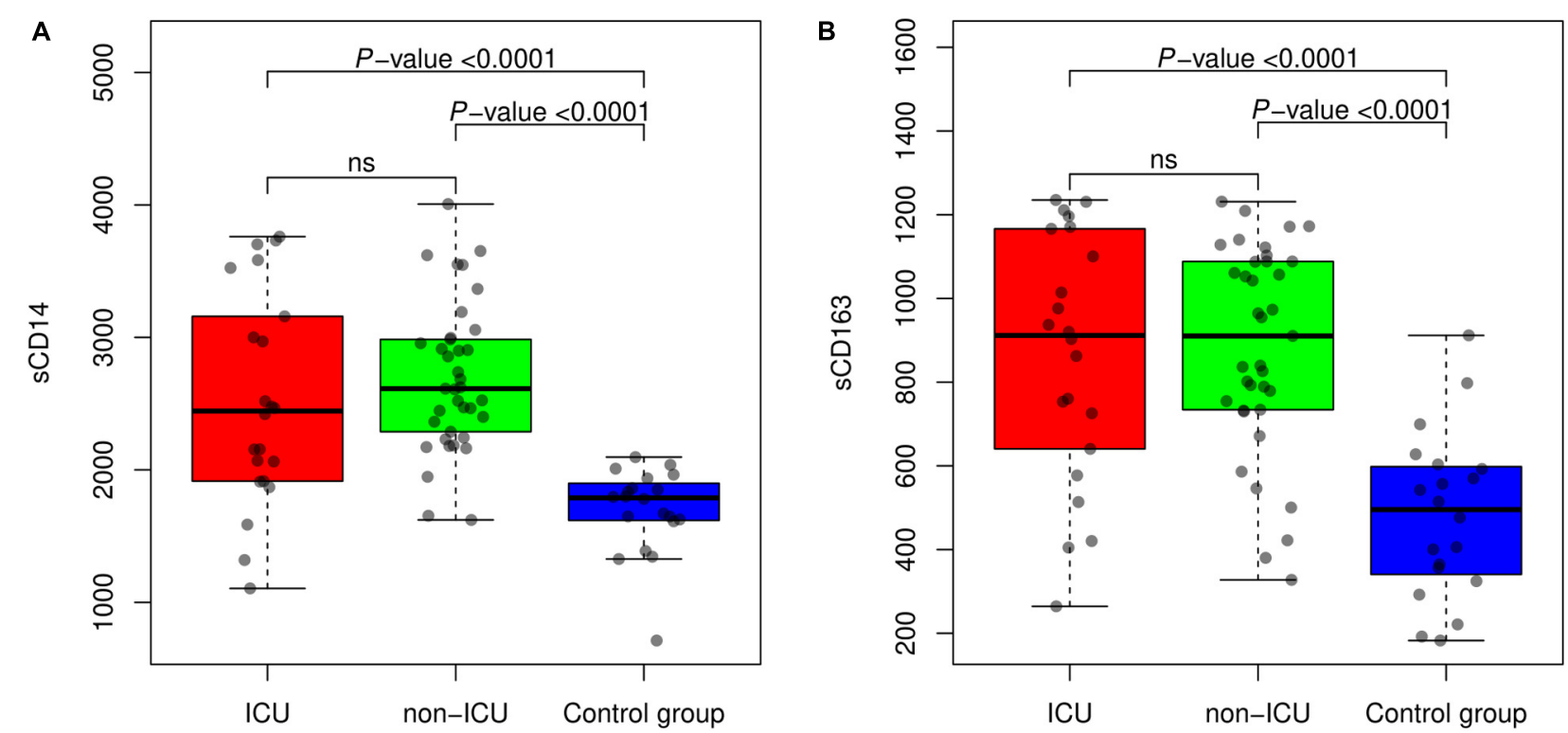

FIGURE 1 | Values of sCD14 (A) and sCD163 (B) in sera samples from patients in ICU, non-ICU, and healthy controls. Results are presented as median and interquartile range levels in $\mathrm{ng} / \mathrm{ml}$. Non-parametric Mann-Whitney tests were used for comparison between groups, and $P$-values for the different comparisons are displayed.
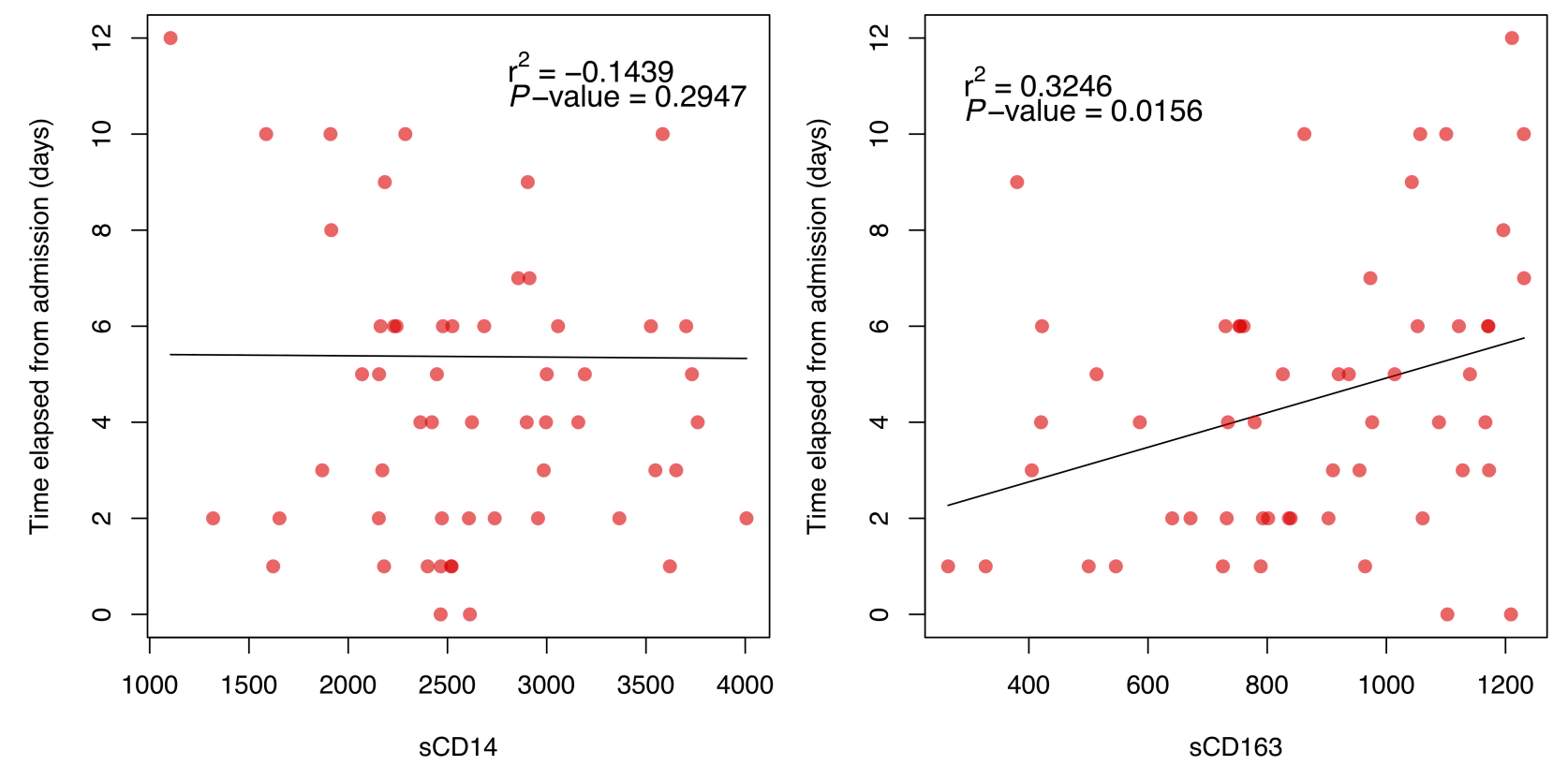

FIGURE 2 | Correlation between serum levels of sCD14 and SCD163 and time elapsed from admission to sample extraction (in days) for all infected patients. Pearson's correlation coefficient $\left(r^{2}\right)$ and $P$-value are shown.

to the interference on monocyte function and sCD14 levels produced by the use of corticoid treatment in ICU patients, as shown here and previously by others $(18,19)$. However, levels of sCD14 showed a strong correlation with clinical laboratory parameters, including acute phase reactants (ferritin, LDH, C-reactive protein, procalcitonin) and a strong correlation with IL-6 levels in the non-ICU patient group, where no corticoids treatments were used. Hydroxychloroquine and tocilizumab treatment did not show interferences on sCD14 and sCD163 levels. Furthermore, sCD163 levels showed a correlation with the time elapsed from hospital admission to sample extraction, suggesting a potential indicator of disease progression.

Monocytes and macrophages constitute a key component of immune responses against viruses, acting as bridge between 

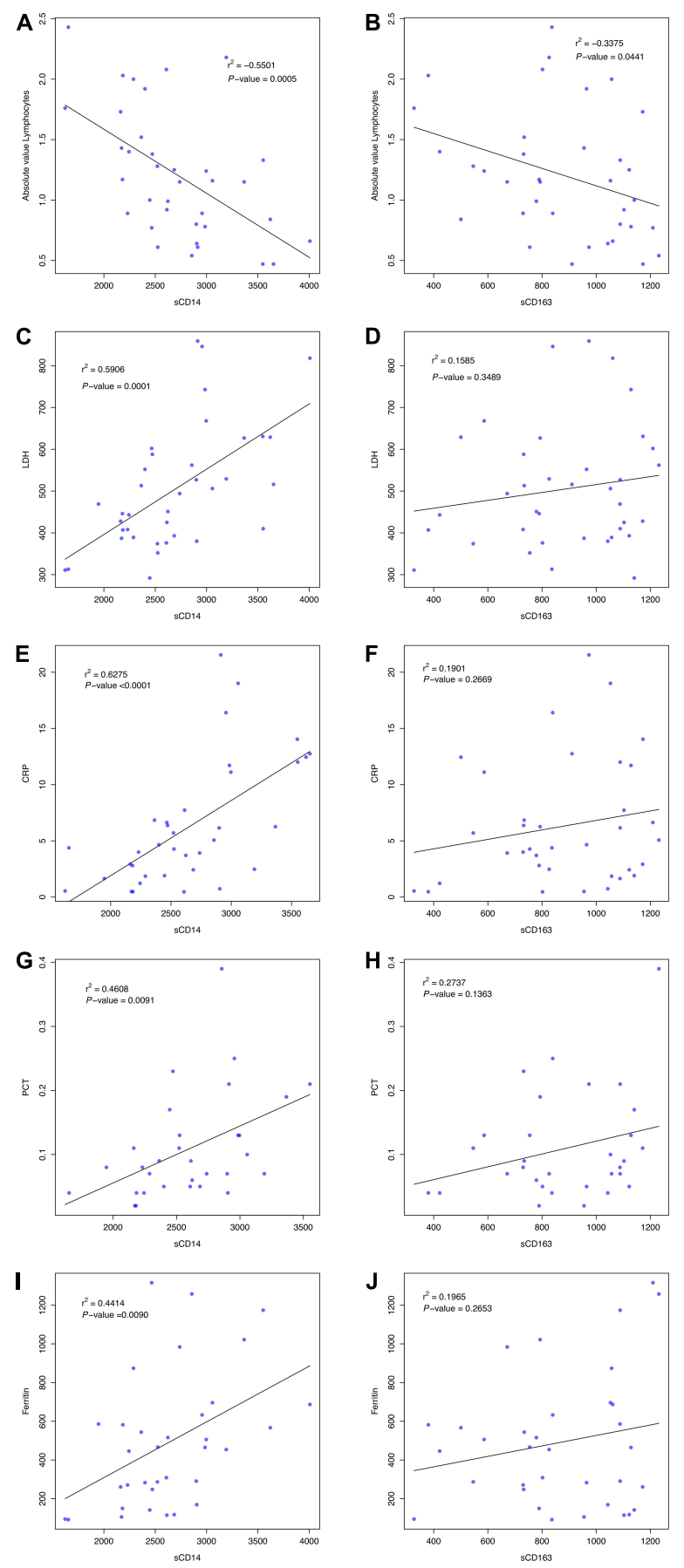

FIGURE 3 | Association between serum levels of SCD14 and SCD163, and several laboratory parameters including Absolute Valor Lymphocytes (A,B), $\mathrm{LDH}(\mathbf{C}, \mathbf{D}), \mathrm{CRP}(\mathbf{E}, \mathbf{F}), \mathrm{PCT}(\mathbf{G}, \mathbf{H})$, and Ferritin $\mathbf{( I , J )}$ in the non-ICU patient group. Pearson's correlation coefficient $\left(r^{2}\right)$ and $P$-value are shown. LDH, lactate dehydrogenase; CRP, C-reactive protein; PCT, procalcitonin.

innate and adaptive immunity (20). Activation of macrophages has been demonstrated to be pivotal in the pathogenesis of the immunosuppression associated to several viral infections (such as VIH, measles), where expansion of specific subsets of

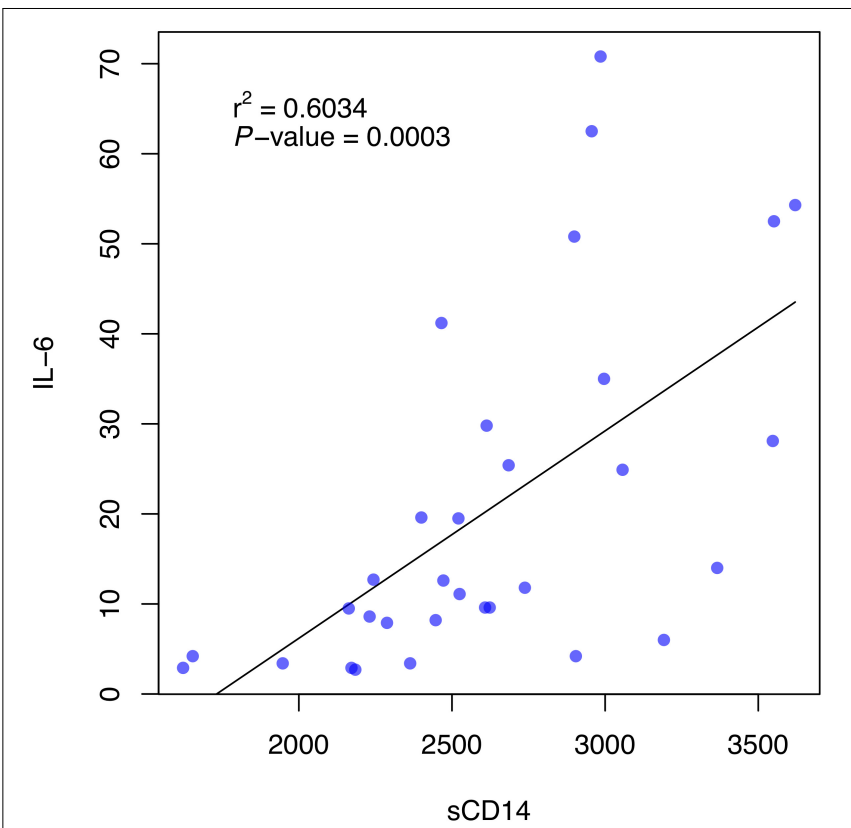

FIGURE 4 | Association between serum levels of sCD14 and IL-6 levels in the non-ICU patient group. Pearson's correlation coefficient $\left(r^{2}\right)$ and $P$-value are presented.

monocytes and macrophages in peripheral blood are observed, and considered to be drivers of immunopathogenesis (21). Our results support the hypothesis of a preponderant role for monocytes in SARS-Cov-2 immunopathology, associated to an overexuberant immune response. Increased levels of monocytemacrophage activation markers, and their correlation with other inflammatory biomarkers (particularly IL-6), indicate a close relationship between monocyte activation and immunopathology in these patients. Inflammatory markers are closely related to severity in COVID-19 pathology (22) and selective blockade of IL-6 has been demonstrated to be a good therapeutic strategy in COVID-19 pathology (23). Our results thus suggest that monocyte-macrophage activation can act as driver cells of the cytokine storm and immunopathology associated to severe clinical course of COVID-19 patients. Further, monitorization of monocyte activity trough these soluble activation markers and/or follow-up of circulating inflammatory monocytes in peripheral blood, could be useful to assess disease progression in the same way as in other viral infections (16).

In addition, our results identify monocyte-macrophage as a good target for the design of therapeutic intervention using drugs that inhibit monocyte-macrophage activation and differentiation. In this sense, anti-GM CSF inhibitor drugs, currently under clinical trials for rheumatic and other auto-inflammatory diseases, might provide satisfactory results in COVID-19 patients. Other drugs targeting monocyte and/or macrophage could also be useful in COVID-19, as in other inflammatory diseases (24). The strategy of inhibiting monocyte differentiation has proved useful in avoiding cytokine storm syndrome after CAR-T cell immunotherapy (25), suggesting a possible therapeutic application to COVID-19 immunopathology $(26,27)$. 

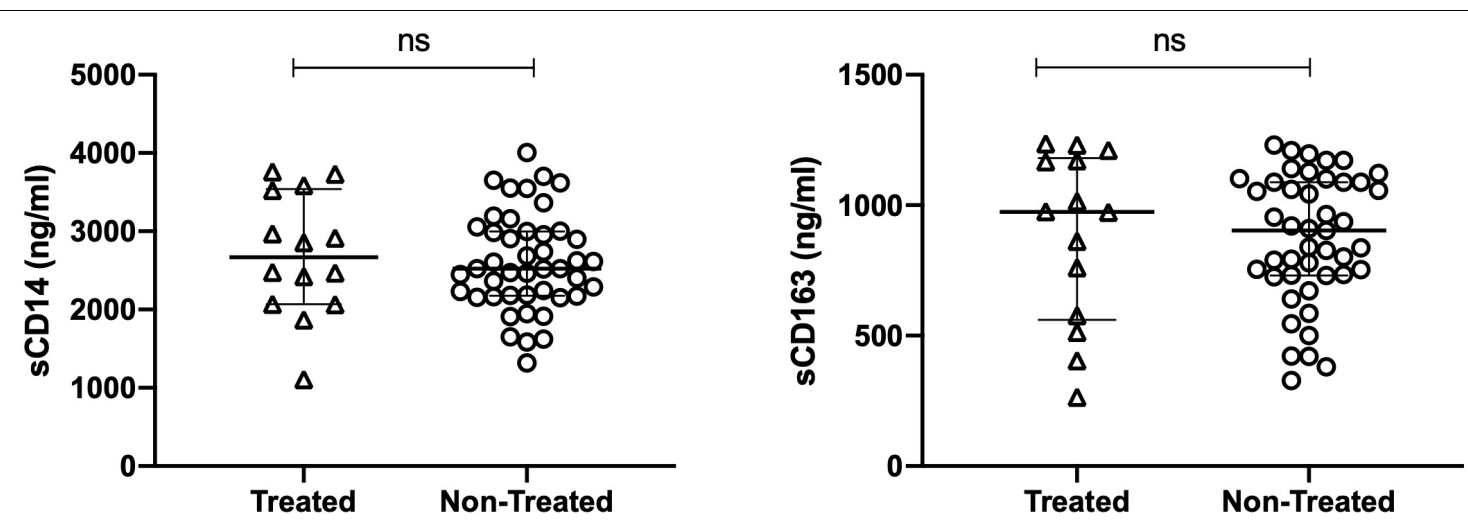

\section{Tocilizumab}
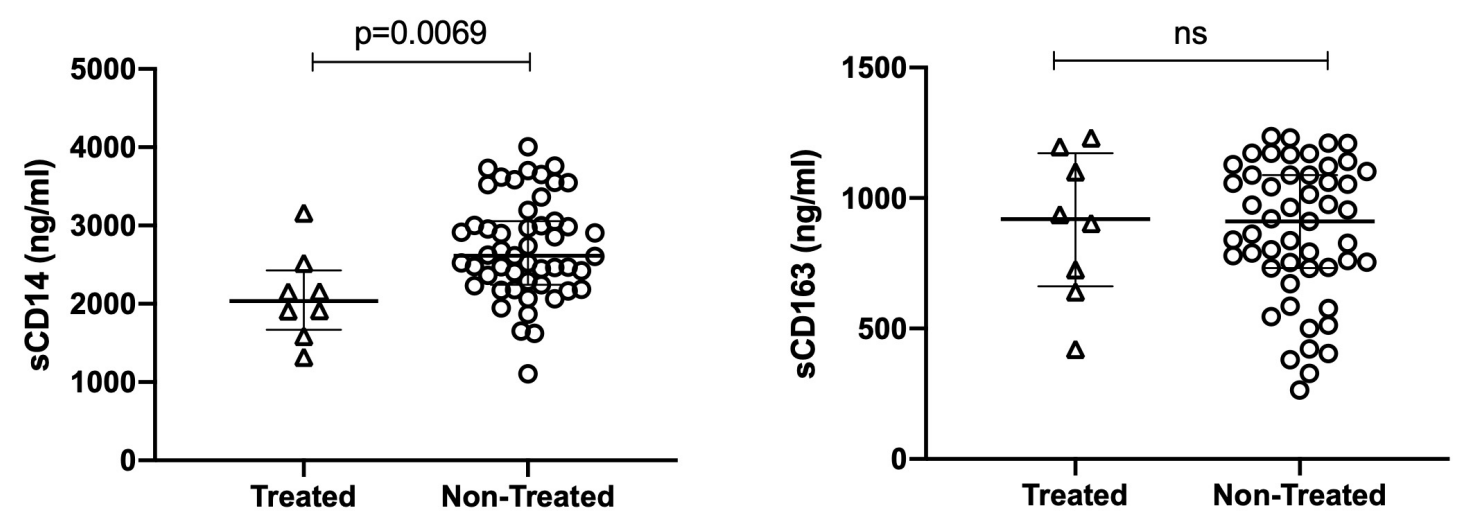

\section{Corticoids}
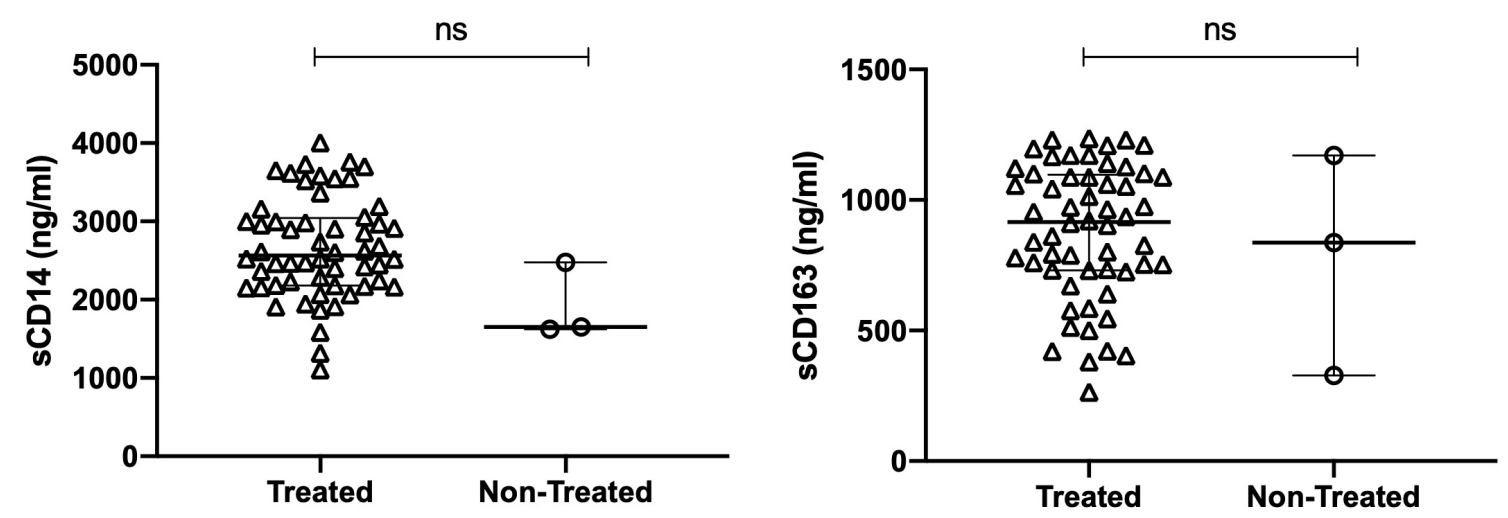

\section{Hydroxychloroquine}


The present study has several limitations, including a relatively low sample size and the interference of corticoids in ICU patients' results. However, these preliminary results are strongly suggestive of an important implication of monocytemacrophage in COVID-19 immunopathology, as highlighted by the correlations found between these biomarker levels and inflammatory parameters. Further studies using broader series are needed to confirm our findings.

In summary, our data underscore the preponderant role of monocyte and macrophage immune response in COVID-19 immunopathology and provide pointers for future interventions in drug strategies and monitoring plans for these patients.

\section{DATA AVAILABILITY STATEMENT}

The raw data supporting the conclusions of this article will be made available by the authors, without undue reservation.

\section{ETHICS STATEMENT}

The studies involving human participants were reviewed and approved by Comité de Ética de la Investigación con Medicamentos de Galicia (fast-track approval 18-march-2020). Written informed consent to participate in this study was provided by the participants' legal guardian/next of kin.

\section{AUTHOR CONTRIBUTIONS}

JG-R, FM-T, and AS designed and conceptualized the study and made the first draft. MC-T, IR-C, AG-C, MC-L, CR-T, AD-U, CR-V, NR-N, RT-P, and JR-G collected the samples and did the analysis, reviewed the draft and approved the final version. All authors contributed to the article and approved the submitted version.

\section{FUNDING}

This study received support from the Instituto de Salud Carlos III: project GePEM (Instituto de Salud Carlos III(ISCIII)/PI16/01478/Cofinanciado FEDER), DIAVIR (Instituto de Salud Carlos III(ISCIII)/DTS19/00049/ Cofinanciado FEDER; Proyecto de Desarrollo Tecnológico

\section{REFERENCES}

1. Liao M, Liu Y, Yuan J, Wen Y, Xu G, Zhao J, et al. The landscape of lung bronchoalveolar immune cells in COVID-19 revealed by single-cell RNA sequencing. medRxiv. (2020). [Preprint]. doi: 10.1101/2020.02.23.20026690

2. Zhang D, Guo R, Lei L, Liu H, Wang Y, Wang Y, et al. COVID-19 infection induces readily detectable morphological and inflammation-related phenotypic changes in peripheral blood monocytes, the severity of wich correlate with patient outcome. medRxiv. (2020). [Preprint]. doi: 10.1101/ 2020.03.24.20042655

3. Mehta P, McAuley DF, Brown M, Sanchez E, Tattersall RS, Manson JJ, et al. Speciality Collaboration, COVID-19: consider cytokine storm syndromes en Salud) and Resvi-Omics (Instituto de Salud Carlos III(ISCIII)/PI19/01039/Cofinanciado FEDER) and project BIBACVIR (PRIS-3; Agencia de Conocimiento en Salud (ACIS)— Servicio Gallego de Salud (SERGAS) - Xunta de Galicia; Spain) given to AS; and projects ReSVinext (Instituto de Salud Carlos III(ISCIII)/PI16/01569/Cofinanciado FEDER), and Enterogen (Instituto de Salud Carlos III(ISCIII)/PI19/01090/Cofinanciado FEDER) given to FM-T.

\section{ACKNOWLEDGMENTS}

This work was developed with support from the GENCOVID Study Group (www.gencovid.eu) from the Hospital Clínico Universitario de Santiago de Compostela, Instituto de Investigación Sanitaria de Santiago and Universidad de Santiago de Compostela, whose members are: Aguilera Guirao, Antonio; Álvarez Escudero, Julián; Antela López, Antonio; Barbeito Castiñeiras, Gema; Bello Paderne, Xabier; Ben García, Miriam; Carral García, María Victoria; Cebey López, Miriam; Coira Nieto, Amparo; Conde Pájaro, Mónica; Costa Alcalde, José Javier; Currás Tuala, María José; Dacosta Urbieta, Ana Isabel; Díaz Esteban, Blanca; Domínguez Santalla, María Jesús; Fernández Villaverde, Juan; Galbán Rodríguez, Cristóbal; García Allut, José Luis; García Vicente, Luisa; Giráldez Vázquez, Elena; Gómez Carballa, Albertoํㅜ Gómez Rial, José; González Barcala, Francisco Javier; Guerra Liñares, Beatriz; Leboráns Iglesias, Pilar; Lence Massa, Beatriz; Lendoiro Fuentes, Marta; López Franco, Montserrat; López Lago, Ana; Navarro De la Cruz, Daniel; Núñez Masid, Eloína; Ortolá Devesa, Juan Bautista; Pardo Seco, Jacobo; Pazo Núñez, María; Pérez del Molino Bernal, Marisa; Pérez Freixo, Hugo; Piñeiro Rodríguez, Lidia; Pischedda, Sara; Portela Romero, Manuel; Pose Reino, Antonio; Prada Hervella, Gloria María; Queiro Verdes, Teresa; Redondo Collazo, Lorenzo; Regueiro Casuso, Patricia; Rey García, Susana; Rey Vázquez, Sara; Riveiro Blanco, Vanessa; Rivero Calle, Irene; Rivero Velasco, Carmen; Rodríguez Núñez, Nuria; Rodríguez-Tenreiro Sánchez, Carmen; Saborido Paz, Eva; Sadiki Orayyou, José Miguel; Saito Villanueva, Carla; Serén Fernández, Sonia; Souto Sanmartín, Pablo; Taboada Muñiz, Manuel; Trastoy Pena, Rocío; Treviño Castellano, Mercedes; Valdés Cuadrado, Luis; Varela García, Pablo; Vilas Iglesias, María Soledad; Viz Lasheras, Sandra. We would like to acknowledge the effort of all first-line healthcare workers supporting the patients included in this study.

and immunosuppression. Lancet. (2020) 395:1033-4. doi: 10.1016/S01406736(20)30628-0

4. McKenna RW, Risdall RJ, Brunning RD. Virus associated hemophagocytic syndrome. Hum Pathol. (1981) 12:395-8. doi: 10.1016/S0046-8177(81) 80019-6

5. Emminger W, Zlabinger GJ, Fritsch G, Urbanek R. CD14(dim)/CD16(bright) monocytes in hemophagocytic lymphohistiocytosis. Eur J Immunol. (2001) 31:1716-9. doi: 10.1002/1521-4141(200106)31:6<1716::AID-IMMU1716>3. $0 . \mathrm{CO} ; 2-\mathrm{X}$

6. Brisse E, Wouters $\mathrm{CH}$, Andrei G, Matthys P. How viruses contribute to the pathogenesis of hemophagocytic lymphohistiocytosis. Front Immunol. (2017) 8:1102. doi: 10.3389/fimmu.2017.01102 
7. La Rosee P, Horne A, Hines M, von Bahr Greenwood T, Machowicz R, Berliner N, et al. Recommendations for the management of hemophagocytic lymphohistiocytosis in adults. Blood. (2019) 133:2465-77. doi: 10.1182/blood. 2018894618

8. Beutel G, Wiesner O, Eder M, Hafer C, Schneider AS, Kielstein JT, et al. Virus-associated hemophagocytic syndrome as a major contributor to death in patients with 2009 influenza A (H1N1) infection. Crit Care. (2011) 15:R80. doi: $10.1186 /$ cc10073

9. Al-Ahmari A. Is secondary hemophagocytic lymphohistiocytosis behind the high fatality rate in Middle East respiratory syndrome corona virus? J Appl Hematol. (2015) 6:1-5. doi: 10.4103/1658-5127.155168

10. Ye Q, Wang B, Mao J. The pathogenesis and treatment of the 'Cytokine Storm' in COVID-19. J Infect. (2020) 80:607-13. doi: 10.1016/j.jinf.2020. 03.037

11. Shive CL, Jiang W, Anthony DD, Lederman MM. Soluble CD14 is a nonspecific marker of monocyte activation. AIDS. (2015) 29:1263-5. doi: 10.1097/QAD.0000000000000735

12. Tippett E, Cheng WJ, Westhorpe C, Cameron PU, Brew BJ, Lewin SR, et al. Differential expression of CD163 on monocyte subsets in healthy and HIV-1 infected individuals. PLoS One. (2011) 6:e19968. doi: 10.1371/journal.pone. 0019968

13. Sandler NG, Wand H, Roque A, Law M, Nason MC, Nixon DE, et al. Plasma levels of soluble CD14 independently predict mortality in HIV infection. J Infect Dis. (2011) 203:780-90. doi: 10.1093/infdis/jiq118

14. Lien E, Aukrust P, Sundan A, Muller F, Froland SS, Espevik T. Elevated levels of serum-soluble CD14 in human immunodeficiency virus type 1 (HIV-1) infection: correlation to disease progression and clinical events. Blood. (1998) 92:2084-92. doi: 10.1182/blood.V92.6.2084.418k26_2084_2092

15. Lederman MM, Calabrese L, Funderburg NT, Clagett B, Medvik K, Bonilla $\mathrm{H}$, et al. Immunologic failure despite suppressive antiretroviral therapy is related to activation and turnover of memory CD4 cells. J Infect Dis. (2011) 204:1217-26. doi: 10.1093/infdis/jir507

16. Burdo TH, Soulas C, Orzechowski K, Button J, Krishnan A, Sugimoto C, et al. Increased monocyte turnover from bone marrow correlates with severity of SIV encephalitis and CD163 levels in plasma. PLoS Pathog. (2010) 6:e1000842. doi: 10.1371/journal.ppat.1000842

17. Mascia C, Pozzetto I, Kertusha B, Marocco R, Del Borgo C, Tieghi T, et al. Persistent high plasma levels of sCD163 and sCD14 in adult patients with measles virus infection. PLoS One. (2018) 13:e0198174. doi: 10.1371/journal. pone.0198174

18. Obeng JA, Amoruso A, Camaschella GL, Sola D, Brunelleschi S, Fresu LG. Modulation of human monocyte/macrophage activity by tocilizumab, abatacept and etanercept: an in vitro study. Eur J Pharmacol. (2016) 780:33-7. doi: 10.1016/j.ejphar.2016.03.028
19. Rinehart JJ, Balcerzak SP, Sagone AL, LoBuglio AF. Effects of corticosteroids on human monocyte function. J Clin Invest. (1974) 54:1337-43. doi: 10.1172/ JCI107880

20. Christensen JE, Thomsen AR. Co-ordinating innate and adaptive immunity to viral infection: mobility is the key. APMIS. (2009) 117:338-55. doi: 10.1111/j. 1600-0463.2009.02451.x

21. Burdo TH, Lo J, Abbara S, Wei J, DeLelys ME, Preffer F, et al. Soluble CD163, a novel marker of activated macrophages, is elevated and associated with noncalcified coronary plaque in HIV-infected patients. J Infect Dis. (2011) 204:1227-36. doi: 10.1093/infdis/jir520

22. Gong J, Dong H, Xia SQ, Huang YZ, Wang D, Zhao Y, et al. Correlation analysis between disease severity and inflammation-related parameters in patients with COVID-19 pneumonia. medRxiv. (2020). [Preprint]. doi: 10. $1101 / 2020.02 .25 .20025643$

23. Zhang $\mathrm{C}, \mathrm{Wu} \mathrm{Z}, \mathrm{Li}$ JW, Zhao H, Wang GQ. The cytokine release syndrome (CRS) of severe COVID-19 and Interleukin-6 receptor (IL-6R) antagonist Tocilizumab may be the key to reduce the mortality. Int J Antimicrob Agents. (2020) 55:105954. doi: 10.1016/j.ijantimicag.2020.105954

24. He W, Kapate N, Shields CWT, Mitragotri S. Drug delivery to macrophages: a review of targeting drugs and drug carriers to macrophages for inflammatory diseases. Adv Drug Deliv Rev. (2019) (in press). doi: 10.1016/j.addr.2019.12.001

25. Sterner RM, Sakemura R, Cox MJ, Yang N, Khadka RH, Forsman $\mathrm{CL}$, et al. GM-CSF inhibition reduces cytokine release syndrome and neuroinflammation but enhances CAR-T cell function in xenografts. Blood. (2019) 133:697-709. doi: 10.1182/blood-2018-10-881722

26. Gomez-Rial J, Martinon-Torres F. A strategy targeting monocyte-macrophage differentiation to avoid pulmonary complications in sars-cov2 infection. Clin Immunol. (2020) 216:108442. doi: 10.1016/j.clim.2020.108442

27. Gomez-Rial J, Rivero-Calle I, Salas A, Martinon-Torres F. Role of monocytes/ macrophages in covid-19 pathogenesis: implications for therapy. Infect. Drug Resist. (2020) 13:2485-2493. doi: 10.2147/IDR.S258639

Conflict of Interest: The authors declare that the research was conducted in the absence of any commercial or financial relationships that could be construed as a potential conflict of interest.

Copyright (C) 2020 Gómez-Rial, Currás-Tuala, Rivero-Calle, Gómez-Carballa, CebeyLópez, Rodríguez-Tenreiro, Dacosta-Urbieta, Rivero-Velasco, Rodríguez-Núñez, Trastoy-Pena, Rodríguez-García, Salas and Martinón-Torres. This is an open-access article distributed under the terms of the Creative Commons Attribution License (CC BY). The use, distribution or reproduction in other forums is permitted, provided the original author(s) and the copyright owner(s) are credited and that the original publication in this journal is cited, in accordance with accepted academic practice. No use, distribution or reproduction is permitted which does not comply with these terms. 